\title{
Super especialização na cirurgia geral - problema ou solução?
}

\section{Super specialization in general surgery - a problem or the solution?}

\author{
ElizABEth G. SANTOS,TCBC-RJ
}

\author{
"Quality surgical education and training is not about \\ producing half-trained surgeons..." \\ (Collins JP, Gough IR, Civil DI, Stitz RWZ, 2007)?
}

\author{
R E S U M O
}

\begin{abstract}
A cirurgia geral atualmente é considerada, por alguns, como uma especialidade cansativa, desinteressante. Acredita-se que o aparecimento de novas tecnologias, a internet, a videocirurgia, a robótica, a telemedicina, a especialização e o desinteresse, dos recém formados, pela cirurgia geral são fatores que contribuem para esta mudança. Neste artigo são discutidas as mudanças no exercício da cirurgia geral que ocorrem no Brasil, no mundo, as suas consequencias na formação do Cirurgião Geral e o reflexo no atendimento à população.
\end{abstract}

Descritores: Cirurgia Geral. Especialidades. Internato e Residência. Educação. Ensino.

\section{INTRODUÇÃO}

O reino da Cirurgia Geral está sob forte ataque. Seus inimigos possuem armas poderosas, de longo alcance e efeitos devastadores. A extinção do Cirurgião Geral se aproxima célere.

Das pesquisas até o fim do século XIX veio o conhecimento do que parecia ser o máximo da evolução da medicina: controle da hemostasia, da infecção e da anestesia. Conhecimentos tão básicos para a cirurgia que, nos dias atuais, parece irreal que um dia já foram desconhecidos. A partir daí, as operações puderam ser realizadas com grandes chances de sucesso. A medicina evoluiu nos últimos 20 anos, muito mais do que até então. O aparecimento de novas tecnologias, estudos profundos sobre fisiologia e fisiopatologia, a internet, a videocirurgia, a robótica, a telemedicina, etc., mudaram para sempre o modelo proposto por Halsted (bastante influenciado por seu estágio na Alemanha), em 1889, nos Estados Unidos, para o ensino da Cirurgia após a graduação: treinamento rigoroso, amplo, profundo e longo, em todas as áreas cirúrgicas, e dedicação total. Naquele tempo o jovem cirurgião em formação, adquiria e desenvolvia a habilidade técnica ao auxiliar seu Mestre e conquistava competências, como profissionalismo, ao observá-lo nos diferentes cenários do cotidiano da prática médica ${ }^{2,3}$. Ao propor aquele tipo de treinamento, Halsted definiu o que seria a Cirurgia Geral; na época, muito mais para cirurgia em geral. Mesmo com toda a mudança e sofisticação tecnológica, uma única coisa não mudou: o princípio Hipocrático da não maleficência; a exigência de, sob qualquer circunstância, manter-se a segurança do paciente.
Várias áreas da Medicina rapidamente se desenvolveram. e teve início, então, a especialização. Nos Estados Unidos, a otorrinolaringologia foi a primeira especialidade a se separar da Cirurgia Geral, em 1924. No Brasil, embora vários grupos de cirurgiões, atuando na mesma área de interesse, surgissem aos poucos, foi só em 1957 que o Conselho Federal de Medicina outorgou Títulos de Especialista a algumas sociedades médicas conveniadas à Associação Médica Brasileira, entre elas o Colégio Brasileiro de Cirurgiões ( $C B C$ ) e a Sociedade Brasileira de Cirurgia Plástica. Porém, antes mesmo que o CBC fosse fundado (1929), a Sociedade Brasileira de Oftalmologia já tinha seu estatuto e seus sócios (1922) e, logo depois, a Urologia também estabeleceria sua Sociedade $(1926)^{4}$.

Atualmente observamos o aparecimento de várias áreas de micro fragmentações da Cirurgia Geral, de crescente interesse entre os cirurgiões, fato que pode ser comprovado pela proliferação das Sociedades Cirúrgicas. A mais recente no Rio de Janeiro, em dezembro de 2009, a Sociededade Brasileira de Hérnia e Parede Abdominal. Algumas destas áreas demandam treinamento profundo e demorado, o que pode afetar a qualidade do profissional lançado no mercado de trabalho, haja vista que o atual tempo de formação é exíguo, tanto para a Cirurgia Geral quanto para qualquer super especialidade. Em curto prazo não teremos mais cirurgiões capacitados para atender aos pacientes politraumatizados, aos que chegam nas emergências ou aqueles que residem a mais de $50 \mathrm{Km}$ dos grandes hospitais. Em breve não teremos mais candidatos habilitados à concessão do Título de Especialista em Cirurgia Geral.

Mestre em Cirurgia Geral pela UFRJ. Coordenadora do Programa de Residência Médica em Cirurgia Geral e Cirurgia Geral - Programa Avançado - HUCFF/UFRJ. 
A compartimentalização da Cirurgia Geral, que começou sob a égide de oferecer o padrão máximo de qualidade no atendimento ao paciente, aquele que o super especialista ofereceria, porque seria aquele que, em tese, dominaria totalmente aquela área do saber; também está fortemente ligada ao fator financeiro. Tem-se a veleidade de achar que, quanto menor for o número de cirurgiões aptos para realizar tal ou qual procedimento, serão melhor remunerados pelos planos e seguradoras de saúde. A partir desta interpretação acordos têm sido feitos com tais entidades de saúde, começando (ou terminando) com a tabela de remuneração de procedimentos (idealizada por médicos), cujo exemplar utilizado por vários planos é de 1990, outros usam um de 1992 e pouquíssimos se baseiam em um terceiro, ao qual se aplicam deflatores para cálculo da remuneração ${ }^{5}$ Todas estas tabelas, totalmente fora da realidade econômica do país, representam uma agressão, para dizer o mínimo, para todos os médicos, cirurgiões ou não.

O progressivo desinteresse de recém-formados pela Cirurgia Geral vem sendo observado há alguns anos. Esse não é um fato exclusivo do Brasil; muito tem sido discutido, como causas do fato e suas repercussões na prática médica. Em várias pesquisas com alunos do curso de graduação em Medicina constatou-se que, mesmo antes da formatura, eles já pensam na especialização e não veem a Cirurgia Geral como opção. Alguns poucos veem a importância da especialidade e outros optam por certas especialidades, seduzidos pela ilusão de alcançar sucesso social e financeiro ${ }^{6}$. Os residentes atuais pensam diferente, hoje já não admitem as longas horas passadas nos hospitais com os pacientes e os plantões extras nas Emergências para aprender. A qualidade de vida e a remuneração passaram a ser preponderantes na escolha da especialidade ${ }^{7}$. Segundo Fisher, $70 \%$ dos residentes de Cirurgia Geral nos Estados Unidos escolhem outra especialidade cirúrgica ${ }^{7}$. Segundo Williams Jr et al. no final de 2010, nos Estados Unidos haveria um deficit de 1300 Cirurgiões Gerais.

A abrangência da Cirurgia Geral praticada hoje, em nada se parece com aquela dos tempos de Halsted; ao longo do tempo, foi perdendo território. A especialidade, que era vista por muitos como uma especialidade rica, prazerosa e desafiadora, atualmente deixou de ser vista assim por quase todos os médicos, e é considerada cansativa, desinteressante e mal remunerada, servindo apenas como requisito para as demais especialidades cirúrgicas. Vários fatores estão envolvidos na mudança do atual modelo da prática. Um deles, sem dúvida, é o avanço tecnológico, substituindo por procedimentos minimamente invasivos as grandes operações para as quais os Cirurgiões Gerais treinaram por muitos anos e o que não pode ser resolvido assim, é encaminhado para o super especialista.

O objetivo de um programa de residência em cirurgia é produzir um cirurgião completamente treinado e pronto para o mercado de trabalho'. A residência médica em Cirurgia Geral, no Brasil, passou por várias mudanças desde a sua implantação. Em 1977, quando foi estabelecida, o tempo de duração era de dois anos. Em 1979, foi criado um terceiro ano, o R3, para aprofundamento de conhecimentos, até que a Resolução $n^{\circ} 01$, de 14 de maio de 2002, definiu que a Cirurgia Geral é programa de acesso direto com dois anos de duração cujo conteúdo programático inclui rodízios com duração de 30 dias em dez outras especialidades e é requisito para as residências de sete programas de especialidades cirúrgicas. Em 2004, houve uma nova mudança. Foi criada a Cirurgia Geral Programa Avançado, que quase nada ajudou na formação do Cirurgião Geral, já que são pouquíssimos os hospitais credenciados para o programa, todos na região sudeste e com um número ínfimo de vagas. Fazer da Cirurgia Geral o requisito para as especialidades cirúrgicas minimizando sua importância e a abertura da Cirurgia Geral - Programa Avançado - da forma como está, que não trata quem a faz como Especialista, já que em nada modifica o Título de Especialista concedido pelo MEC de quem o cumpre, só contribuiu para o desprestígio, descaso e desinteresse da especialidade e do especialista. Todos esses fatores têm enormes implicações para a prática da cirurgia, principalmente porque, dos cirurgiões que terminam a residência em Cirurgia Geral, um grande contingente não tem nenhuma oportunidade de continuar seu treinamento $45 \%{ }^{9}$, que acabará após dois anos de uma residência insuficiente, não sendo especialista, nem, muito menos, um Cirurgião Geral. Levando-se em consideração que o Brasíl é um país com extensão territorial de 8.5 milhões de $\mathrm{Km}^{2}$, densidade populacional em torno de 200 milhões de pessoas e que, destas, quase 140 milhões são usuárias do Sistema Único de Saúde ${ }^{10,11}$, fica a pergunta: o modelo de formação atual do Cirurgião Geral garante o padrão máximo de qualidade no atendimento a essa população ?

Hutter ${ }^{12}$ define o especialista como aquele que concentra sua habilidade em determinada operação e que, em relação a esta operação, ele tem menor índice de complicações e menor mortalidade. Em seu editorial, cita vários "benefícios" em ser um especialista, sendo um deles a remuneração e outro a boa vontade do Juiz, na eventualidade de ser processado "afinal, ele é um especialista", passando também por horas bem dormidas e um estilo de vida mais aprazível. Quem pode condenar alguém por querer isto ? Neste mesmo editorial ele diz: " a specialist is a doctor with a smaller practice but a bigger home". Será essa a força do apelo para ser um super especialista ? E onde ficará o Cirurgião Geral ? O que Ihe caberá fazer ? Onde Ihe caberá trabalhar? É do super especialista que a população precisa ? Para cada doença o paciente terá um cirurgião ? Um vai Ihe operar a vesícula, outro o pâncreas, mais um para o cólon, e outro mais para a traqueostomia e, mais tarde, um para o desbridamento das úlceras de pressão ?

Os dados publicados por Dayton ${ }^{13}$ seriam, em princípio, animadores ao revelar que em um estudo realizado por Harms et al ${ }^{14} 75 \%$ dos cirurgiões gerais questionados afirmaram estar satisfeitos com a escolha de sua carreira, porém este mesmo estudo revela que mais de 
$25 \%$ dos cirurgiões especialistas se aposentam por volta dos cinquenta anos de idade.

Afinal, quem é o Cirurgião Geral ? Até o início do Século XX, o Cirurgião, em troca de seus serviços, recebia a admiração de seus colegas, o respeito da sociedade e uma remuneração condizente com sua posição social. E atualmente ? É aquele que primeiro atende o paciente e chama o especialista ? É aquele que só opera as emergências ? É aquele que sabe um pouquinho de tudo, ou de quase nada? "É o especialista com conhecimeto da doença, do diagnóstico e do tratamento das doenças tratáveis por procedimento cirúrgico cuja formação deve prepará-lo para a execução das intervenções cirúrgicas básicas das demais especialidades ?"14 É aquele que recebe honorário insignificante por um procedimento operatório só porque o paciente está internado em enfermaria ? Sua responsabilidade é menor quando o paciente está na enfermaria ?

A formação atual do cirurgião geral, determinada pela Comissão Nacional de Residência Médica, é insuficiente para que ele preencha os critérios essenciais para ser um especialista. Isto somado ao sucateamento dos hos- pitais do Brasil, universitários ou não, transformou a Cirurgia Geral não em uma especialidade, mas em falta de opção para quem deseja ser Cirurgião.

Todo dia algo novo surge no campo da medicina: novas drogas, manipulação genética, a nanotecnologia, a biocirurgia, etc. Chegará o dia em que o cirurgião não mais removerá parte de um órgão, mas atuará na modificação celular ou na implantação de "chips" para controle de órgãos ou funções deficientes. Para isso será necessário um novo sistema de treinamento ${ }^{15}$. Pensar nisso nos dias atuais nos parece menos distante do que teria parecido a Halsted no passado, que um dia as vesículas seriam removidas através do umbigo.

A cirurgia evoluirá ainda mais, com certeza. O futuro do Cirurgião Geral está profundamente ameaçado. Ele corre o risco de desaparecer em poucos anos ${ }^{7}$, de tornar-se um personagem da história. A Cirurgia Geral, como era conhecida e praticada, será exercida, quando muito, na periferia das grandes cidades ou no interior, distante dos grandes centros, por cirurgiões treinados de forma insuficiente, deficiente, mas, Especialistas, após o término de sua Residência Médica com duração de dois anos.

\section{A B S T R A C T}

Nowadays, general surgery is considered as a tiring and uninteresting specialty. It is believed that the advent of new technologies, the internet, videosurgery, robotics, telemedicine, specialization and the indifference of recently graduated for the general surgery may be factors that had contributed to this change. In this article the changes of general surgery practice in Brazil, in the world an their consequences in the general surgeon professional development are being discussed.

Key word: General Surgery. Specialization. Internship and Residency. Education. Teaching.

\section{REFERENCIAS}

1. Collins JP, Gough IR, Civil ID, Stitz RW. A new surgical education and training programme. ANZ J Surg 2007;77(7):497-501.

2. Tuoto EA. William Stewart Halsted - Pioneiro da cirurgia nos Estados Unidos [online]. Rio de Janeiro; 2008. Acessado em: 31 Mai. 2010. Disponível em: pt.shvoong.com/medicine-and-health/ 1812399-william-halsted-pioneiro-da-cirurgia/\#ixzz1 Qgzn2wSz

3. O'Shea JS. Becoming a surgeon in the early 20th century: parallels to the present. J Surg Edu 2008;65(3):236-41.

4. Comissão mista de Especialidades - Suplemento Especial [online]. Jornal da Associação Médica Brasileira. Acessado em: 31 Mai. 2010. Disponível em http://www.amb.org.br/teste/imprensa/jamb/ jamb_2002_abr_esp.pdf

5. Amaral JLG, Giron AM, organizadores. Classificação brasileira hierarquizada de procedimentos médicos [online]. AMB; 2008. Acessado em: 31 Mai. 2010. Disponível em: www.amb.org.br/ teste/cbhpm_2010.htm

6. Pitrez F. A ascenção comportamental do cirurgião. Rev Col Bras Cir 2010;37(2):84-5.

7. Fischer JE. The impending disappearance of the general surgeon. JAMA 2007; 298(18):2191-3.

8. Fraser DR. The coming shortage of surgeons: why they are disappearing and what thar means for our health. JAMA, 2010;303(16):1651-2

9. Ferreira EA, Rasslan S. Surgical education in Brazil. World J Surg 2010;34(5):880-3

10. Brasil. Ministério da Saúde. SUS - a saúde do Brasil [online]. Acessado em: 01 Jun. 2010. Disponível em: http:// portalsaude.saude.gov.br/portalsaude/index.cfm/ ?portal=pagina . visualizarArea\&codArea=345

11. Freitas E. Extensão territorial do Brasil [online]. Acessado em: 01 Jun. 2010. Disponível em: http://www.alunosonline.com.br/geografia/territorio-brasileiro-extensao.html

12. Hutter MM. Specialization: the answer or the problem ? Ann Surg 2009;249(5):717-8.

13. Dayton MT. Caveamus surgeones: five great threats to surgery in the new millennium. Arch Surg 2008:143(7):624-30.

14. Harms BA, Heise CP, Gould JC, Starling JR. A 25-year single institution analysis of health, practice, and fate of general surgeons. Ann Surg 2005;242(4):520-6; discussion 526-9

15. CBC. Definição de cirurgião geral do CBC. Bol Inform Col Bras Cir 1974 jul/ago;48

16. Satava RM, Wolf RK. Disruptive visions: biosurgery. Surg Endosc 2003;17(11):1833-6.

Recebido em 15/12/2010

Aceito para publicação em 10/02/2011

Conflito de interesse: nenhum

Fonte de financiamento: nenhum

\section{Como citar este artigo:}

Santos EG. Super especialização na Cirurgia Geral - problema ou solução ? Rev Col Bras Cir. [periódico na Internet] 2011; 38(6). Disponível em URL: http://www.scielo.br/rcbc

\section{Endereço para correspondência:}

Elizabeth Gomes dos Santos

E-mail: eligsant54@gmail.com 